\title{
Therapeutic potential of bacteriophage in treating Klebsiella pneumoniae B5055-mediated lobar pneumonia in mice
}

\author{
Sanjay Chhibber, Sandeep Kaur and Seema Kumari \\ Department of Microbiology, Panjab University, Chandigarh-160014, India
}

Correspondence

Sanjay Chhibber

sanjaychhibber8@sify.com

\begin{abstract}
Klebsiella pneumoniae causes infections in humans especially in immunocompromised patients. About $80 \%$ of nosocomial infections caused by $K$. pneumoniae are due to multidrug-resistant strains. The emergence of antibiotic-resistant bacterial strains necessitates the exploration of alternative antibacterial therapies, which led our group to study the ability of bacterial viruses (known as bacteriophages or simply phages) to treat mice challenged with K. pneumoniae. Phage SS specific for $K$. pneumoniae B5055 was isolated and characterized, and its potential as a therapeutic agent was evaluated in an experimental model of $K$. pneumoniae-mediated lobar pneumonia in mice. Mice were challenged by intranasal (i.n.) inoculation with bacteria $\left(10^{8}\right.$ c.f.u. $\mathrm{ml}^{-1}$ ). A single intraperitoneal injection of $10^{10}$ p.f.u. $\mathrm{ml}^{-1}$ phage administered immediately after i.n. challenge was sufficient to rescue $100 \%$ of animals from K. pneumoniae-mediated respiratory infections. Administration of the phage preparation $3 \mathrm{~h}$ prior to i.n. bacterial challenge provided significant protection in infected mice, while even $6 \mathrm{~h}$ delay of phage administration after the induction of infection rendered the phage treatment ineffective. The results of this study therefore suggest that the timing of starting the phage therapy after initiation of infection significantly contributes towards the success of the treatment.
\end{abstract}

Received 25 April 2008

Accepted 15 August 2008

\section{INTRODUCTION}

Respiratory tract infections are one of the most common and severe forms of infection treated by health-care practitioners all over the world (File, 2000). Furthermore, hospitalacquired pneumonia is the second most common infection, causing high morbidity and mortality (Maloney \& Jarvis, 1995). Klebsiella pneumoniae is one of the most important causative pathogens of respiratory tract infections in humans (Podschun \& Ullmann, 1998). It alone accounts for 25-43\% of the nosocomial pneumonias caused by Gram-negative bacteria (Doern, 1995), particularly in debilitated patients (Nishi \& Tschiya, 1980), and has a rapidly progressive clinical course that is often complicated by multilobular involvement and lung abscesses (Jay, 1983; Carpenter, 1990), which leaves little time to institute effective antimicrobial treatment. As a result, the mortality rates may reach or exceed $50 \%$ even in treated cases (Graybill et al., 1973; Leowski, 1986; Meyer et al., 1993). The populations at risk are neonates, immunocompromised individuals and patients predisposed by prior surgery or malignancy (Hansen et al., 1977; Hervas et al., 1993). An increase in the populations at risk, and an increase in the emergence of multidrug resistance among K. pneumoniae nosocomial isolates, have renewed interest in the investigation of alternative approaches for the treatment and prophylaxis of respiratory tract infections due to $K$.

Abbreviations: i.n., intranasal; i.p., intraperitoneal. pneumoniae (Yadav et al., 2003). Attempts have been made in recent years to find immunoprophylactic/immunotherapeutic agents for controlling K. pneumoniae-mediated infections (Chhibber \& Bajaj, 1995). However, any approach is not acceptable unless it is safe, effective and inexpensive. In this context, an intriguing approach is the use of bacteriophages (viruses that kill bacteria) to eliminate specific bacterial pathogens (Sulakvelidze et al., 2001; Mathur et al., 2003; Thiel, 2004). The ability of phages to rapidly kill or lyse bacteria, and their specificity makes them effective selfreplicating anti-bacterial drugs of the near future (Matsuzaki et al., 2005; Hanlon, 2007). In the present report, experimental lobar pneumonia induced by $K$. pneumoniae was established in mice and the effectiveness of bacteriophage SS as a treatment was studied.

\section{METHODS}

Bacterial strains and growth media. K. pneumoniae B5055 obtained from Dr Mathia Trautman, Department of Medical Microbiology and Hygiene, Ulm, Germany, and maintained in our laboratory was used. The strain was maintained on nutrient agar slants at $4{ }^{\circ} \mathrm{C}$.

Bacterial inoculum. Bacterial strains maintained on nutrient agar slants were grown in static culture in nutrient broth at $37^{\circ} \mathrm{C}$ for $18 \mathrm{~h}$. Organisms were harvested by centrifugation at 10000 r.p.m. for $15 \mathrm{~min}$, washed three times, and suspended in PBS (0.2 $\mathrm{M}, \mathrm{pH} 7.2)$ to the desired concentration 
Phage isolation and purification. The method of Cerveny et al. (2002) was adopted for the isolation of phages from sewage samples specific for K. pneumoniae B5055. Phage titre was determined using soft agar overlay as described by Adams (1959). Phage plaques were harvested from the agar plate and single phage plaques were purified three times on a host strain by the standard procedure as described by Sambrook et al. (1989). The phage SS was tested for its specificity against 20 clinical isolates of K. pneumoniae by the spot test method.

Phage adsorption rate and one-step growth curve. The adsorption rate of phage SS was determined by the method of Adams (1959). A one-step growth curve was performed in order to determine the burst size and latent period of the phage, as described by Ellis \& Delbruck (1939). It was designed to observe one cycle of adsorption, multiplication and lysis of SS.

Transmission electron microscopy. To observe phage morphology, transmission electron microscopy of the SS phage was performed as described by Goodridge et al. (2003) with some modifications, and the sample was examined with a transmission electron microscope (Hitachi $\mathrm{H} 7500$ ) at $80 \mathrm{kV}$.

Toxicity testing of phage in mice. Male $\mathrm{BALB} / \mathrm{c}$ mice, $6-8$ weeks old, weighing $20-25 \mathrm{~g}$, were used in this study. The toxicity of phage suspension was investigated in mice according to the method of Soothill (1992). Mice were injected with $0.25 \mathrm{ml}$ phage suspension $\left(10^{12}\right.$ p.f.u. $\left.\mathrm{ml}^{-1}\right)$ by the intraperitoneal (i.p.) route in three groups of three mice each. Three uninjected mice were retained as controls. The mice were observed for signs of illness, and rectal temperature was taken hourly during the first $5 \mathrm{~h}$ after injection and then daily for the next 4 days.

Phage half-life in mice. The survival and stability of phage SS was measured in mice according to the method of Cerveny et al. (2002). Uninfected mice were injected i.p. with phage preparation at $10^{10}$ p.f.u. $\mathrm{ml}^{-1}$. At $3,6,12,24,36,48$ and $72 \mathrm{~h}$ post-infection, mice were sacrificed and their peritoneal cavities were subjected to lavage with PBS buffer ( $\mathrm{pH}$ 7.2). A total of $100 \mu \mathrm{l}$ of cardiac blood was collected in $0.05 \mathrm{M}$ EDTA. The lungs were aseptically removed, weighed and homogenized in PBS buffer. Phage titre was measured in all the samples by plaque assay.

Induction of pneumonia in mice by intranasal (i.n.) route. Experimental pneumonia was induced in BALB/c mice with $K$. pneumoniae B5055 following i.n. instillation. To determine the minimum lethal dose in these mice, doses ranging from $10^{2}$ to $10^{8}$ c.f.u. $\mathrm{ml}^{-1}$ were given intranasally. The dose $(50 \mu \mathrm{l}$ inoculum containing $10^{8}$ c.f.u.) giving $100 \%$ infection rate without causing mortality was taken as the optimum dose and animals were observed for 10 days. Two animals each at 1, 2, 3, 5, 7 and 10 post-infection day were sacrificed. Lungs were aseptically removed, homogenized in $5 \mathrm{ml}$ sterile PBS buffer $(\mathrm{pH} 7.2)$ and subjected to bacteriological examination.

Phage protection study. The therapeutic potential of phage SS, specific for K. pneumoniae B5055, was evaluated for its ability to resolve lobar pneumonia in mice. Optimal phage dose was determined following the method of McVay et al. (2007). Two groups of mice (12 mice in each) were used. In group I, all the mice were administered by the i.p. route with $100 \mu$ phage preparation at a m.o.i. [the ratio of infectious agent (e.g. phage or virus) to infection target (e.g. bacterial cell)] of 200 , followed by simultaneous i.n. bacterial challenge. In group II, all the mice were instilled with $50 \mu \mathrm{l}$ i.n. bacterial inoculum $\left(10^{8}\right.$ c.f.u. $\left.\mathrm{ml}^{-1}\right)$, which acted as a control. In both the groups, the animals were monitored for 10 days. Two animals each at days 1, 2, 3, 5, 7 and 10 post-infection were sacrificed, and lungs were aseptically removed and subjected to bacteriological examination as described earlier.
The protective ability of a delayed administration of phage after i.n. bacterial challenge with $K$. pneumoniae B5055 was also studied. Three groups of mice were used (12 mice in each). In group I and II, mice were injected by the i.p. route with $100 \mu \mathrm{l}$ phage preparation at a m.o.i. of 200, at 6 and 24 h, respectively, after bacterial challenge. In group III, all the mice were challenged with bacteria only, and no phage preparation was injected, which acted as a positive control. Animals were monitored for 10 days. Lungs were aseptically removed and subjected to bacteriological examination as described earlier.

The protective ability of a prior administration of phage to i.n. bacterial challenge with K. pneumoniae B5055 was also studied. Four groups of mice were used (12 mice in each). In the first three groups, all the mice were injected by the i.p. route with $100 \mu \mathrm{l}$ phage preparation (m.o.i. of 200), at 3, 6 and $24 \mathrm{~h}$ prior to the i.n. bacterial challenge. In the fourth group no phage preparation was injected, which acted as a control. Animals were monitored for 10 days. The lungs were aseptically removed and subjected to bacteriological examination as described earlier.

Combined phage and antibiotic treatment. The MIC of amikacin for K. pneumoniae B5055 was determined and it was selected for checking efficacy in treatment of lobar pneumonia in mice. Mice were divided into 4 groups of 12 mice each. In group I, all the mice were instilled with $50 \mu$ l i.n. bacterial inoculum $\left(10^{8}\right.$ c.f.u. $\left.\mathrm{ml}^{-1}\right)$, which acted as a control. In group II, mice were injected by the i.p. route with $100 \mu \mathrm{l}$ phage preparation $\left(10^{10}\right.$ p.f.u. $\left.\mathrm{ml}^{-1}\right)$, followed by simultaneous i.n. bacterial challenge. In group III, mice were injected by the i.p. route with $100 \mu \mathrm{l}$ amikacin $(3.75 \mathrm{mg} / 25 \mathrm{~g})$, along with $100 \mu \mathrm{l}$ phage preparation $\left(10^{10}\right.$ p.f.u. $\left.\mathrm{ml}^{-1}\right)$, followed by simultaneous i.n. bacterial challenge. In group IV, mice were injected by the i.p. route, with $100 \mu \mathrm{l}$ amikacin $(3.75 \mathrm{mg} / 25 \mathrm{~g})$ with simultaneous bacterial challenge. Two animals each at 1, 2, 3, 5, 7 and 10 days post-infection were sacrificed and lungs were aseptically removed and subjected to bacteriological examination as described earlier.

Statistical analysis. Results were analysed statistically by applying Student's t-test for comparing bacterial counts in phage-treated mice and phage-untreated control mice. Differences were considered statistically significant if $P$ values were less than 0.05 .

\section{RESULTS AND DISCUSSION}

To examine the efficacy of bacteriophage therapy in resolving lobar pneumonia in mice, phage SS specific for K. pneumoniae B5055 was isolated from sewage samples obtained from different sources in and around the Chandigarh area in India. Phage SS exhibited potent lytic activity and thus was selected for further in vitro and in vivo studies. The phage SS was specific to K. pneumoniae and showed narrow host range as 7 out of 20 clinical isolates tested were found to be sensitive to this phage.

The adsorption rate of SS was determined by mixing phage with an excess of K. pneumoniae B5055 cells, and then nonadsorbed infectious phages were serially diluted and counted. The adsorption rate of SS was found to be $10 \mathrm{~min}$. A onestep growth curve of SS on K. pneumoniae B5055 was produced. The latent period, defined as the time interval between the adsorption and the beginning of the first burst, was about $20 \mathrm{~min}$. The mean burst size was about 98 p.f.u. per bacterial cell, calculated as the ratio of the final count of liberated phage particles to the initial count of infected bacterial cell during the latent period (Fig. 1). Transmission 


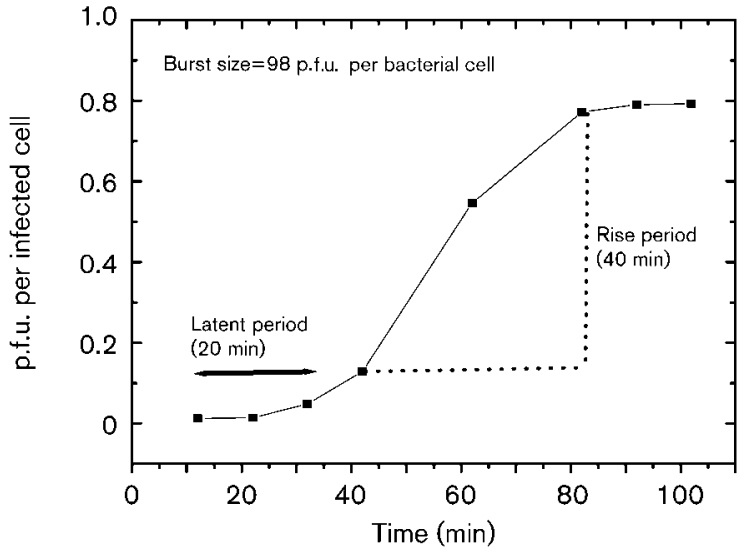

Fig. 1. One-step growth curve of phage SS specific for $K$. pneumoniae B5055.

electron micrograph showed that SS consisted of icosahedral head and short stumpy tail, belonging to morphotype C, subdivision $\mathrm{Cl}$, in the classification proposed by Bradley (1967) and Ackermann (2001). According to International Committee on Taxonomy of viruses, SS phage belongs to family Podoviridae order Caudovirales.

In the present study, the therapeutic potential of a fully characterized phage SS was evaluated in an acute infection model of lobar pneumonia in $\mathrm{BALB} / \mathrm{c}$ mice. The selected phage SS showed no toxicity in mice and thus was considered for further in vivo use. The mean rectal temperature of all the mice injected with bacteriophage SS was $36.7^{\circ} \mathrm{C}$, which was comparable to the temperature of the control group, $37.1{ }^{\circ} \mathrm{C}$. No symptoms of lethargy or sickness were noted in the test group during the period of observation.

Survival and stability of phage SS was measured in mice after i.p. injection of phage preparation containing $3 \times 10^{10}$ p.f.u. $\mathrm{ml}^{-1}$. The phage count was measured in blood, lungs and peritoneal fluid. Maximum phage counts in blood, peritoneal fluid and lungs were obtained $6 \mathrm{~h}$ post injection (Fig. 2). The phage count in peritoneal fluid was slightly higher as compared to that in blood and lungs. The phage count showed a significant decrease of $7 \log$ units at $12 \mathrm{~h}$ and negligible counts were obtained at $36 \mathrm{~h}$ after injection. No phage could be isolated in peritoneal fluid, blood or lungs at $48 \mathrm{~h}$ after phage treatment. The results of survival and stability studies showed that although phage entered into the blood stream after $3 \mathrm{~h}$ they reached their maximum concentration at $6 \mathrm{~h}$ post injection. These results are supported by earlier findings of Bogovazova et al. (1991, 1992), who studied immunological properties and therapeutic effectiveness of bacteriophage. According to these workers, phages took a maximum of $2-4 \mathrm{~h}$ to reach their peak in the blood stream and approximately $6-8 \mathrm{~h}$ to reach their peak in various internal organs. The phage count showed a significant decrease at $12 \mathrm{~h}$ and no phage was detected at $48 \mathrm{~h}$ post-injection in all these samples

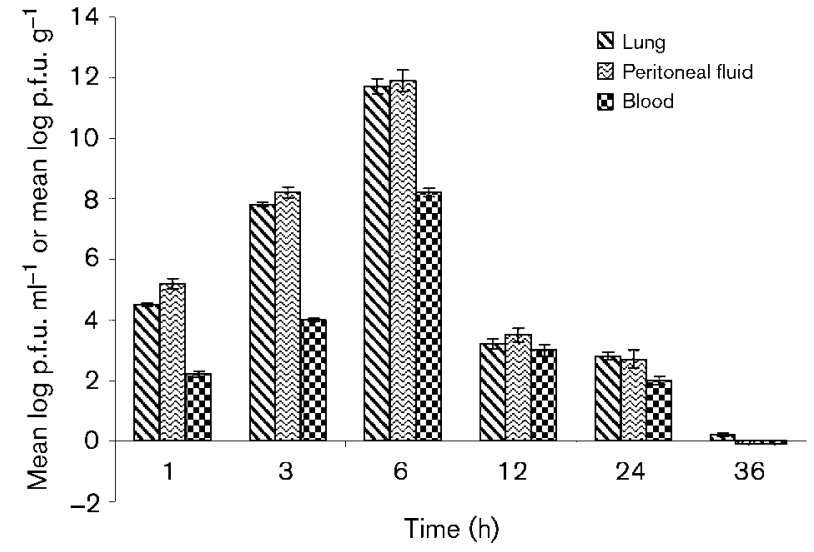

Fig. 2. Phage count in blood (mean log p.f.u. $\mathrm{ml}^{-1}$ ), peritoneal lavage fluid (mean log p.f.u. $\mathrm{ml}^{-1}$ ) and lung homogenate (mean log p.f.u. $\left.\mathrm{g}^{-1}\right)$ at varying time periods after phage administration $\left(10^{12}\right.$ p.f.u. $\mathrm{ml}^{-1}$ ) in BALB/c mice.

The course of acute infection in mouse lung tissue was studied on the basis of maximum colonizing ability of $K$. pneumoniae. There was a significant increase in the bacterial counts on the second and third day post-infection as compared to the first day. The peak bacterial count was observed on the third day post-infection, following which there was a decrease in the bacterial counts, and only negligible counts were observed on the seventh day $(P<0.01)$. There was complete clearance of bacteria from the lungs of infected mice on the tenth day of infection.

An optimum therapeutic dosage of phage preparation was assessed in experimentally induced lobar pneumonia in $\mathrm{BALB} / \mathrm{c}$ mice. In the immediate phage treatment group, the animals in the test group were administered by the i.p. route with $10^{10}$ p.f.u. $\mathrm{ml}^{-1}$ of phage preparation, immediately after i.n. bacterial challenge. Lung bacterial counts in the phagetreated group were comparable to that of the control infected group after $24 \mathrm{~h}$ of treatment (Fig. 3). The bacteria in the phage-treated group did not show any further rise in their number. A significant decrease of $8 \log$ units was observed on the third day in the phage-treated group $(P<0.001)$. Complete clearance of bacteria from lungs occurred on the fifth post-infection day in the phage-treated mice in contrast to the 10 days required for the resolution of infection in the untreated control group. The initial delay in phage action may be due to the time taken $(6 \mathrm{~h})$ by phage to reach their maximum concentration in the lungs. But as the phage growth occurred exponentially in the presence of host bacteria, the phage particles finally took control of the bacterial population by restricting their further growth. This inference is based on the fact that the bacterial count on the second post-infection day did not show any increase in number and was followed by a decline in bacterial growth on subsequent days.

Delayed treatment with phage after induction of bacterial infection was also studied. In the delayed phage treatment 


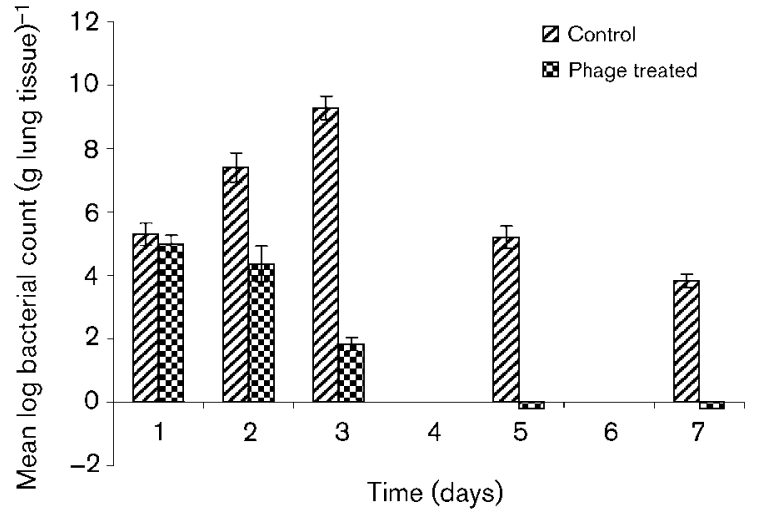

Fig. 3. Bacterial counts in lung tissue homogenate following infection with $K$. pneumoniae B5055 $\left(10^{8}\right.$ c.f.u. $\left.\mathrm{ml}^{-1}\right)$ in BALB/c mice (control) and treatment with phage $\left(10^{10}\right.$ p.f.u. $\mathrm{ml}^{-1}$ ) (phage treated).

group, the animals in the test group were administered by the i.p. route with phage preparation $\left(10^{10}\right.$ p.f.u. $\left.\mathrm{ml}^{-1}\right)$ at 6 and $24 \mathrm{~h}$ post-infection. The results showed that a delay of even $6 \mathrm{~h}$ rendered phage treatment ineffective $(P>0.05)$. Bacterial counts in the lungs of the phage-treated animals were similar to the untreated control at all time points (Fig. 4). This may be due to the time taken by phages $(6 \mathrm{~h})$ to gain access in lungs at an optimum protective dose. This delay in phage administration gives sufficient time (12 h) for the bacteria to increase to a level where their growth cannot be controlled by phages. The phages are generally effective in treating acute infections by bringing the bacterial population down to a low density (Levin \& Bull, 1996). However, they are ineffective in situations where they fail to reduce their number. Similar results were reported by Cerveny et al. (2002) while trying to treat local and systemic disease caused by Vibrio vulnificus in irondextran-treated mice.

In prior phage treatment group, the mice were administered by the i.p. route, with $10^{10}$ p.f.u. $\mathrm{ml}^{-1}$ of phage preparation at 3,6 and $24 \mathrm{~h}$ prior to i.n. bacterial challenge. Administration of phage, $3 \mathrm{~h}$ prior to i.n. bacterial challenge proved most effective $(P<0.001)$ and the results were similar to that observed in the group that was administered phage preparation immediately after bacterial challenge. It is likely that in such a situation, when bacteria entered the lungs, the phages were already present in large numbers and took control of the bacterial population. However, administration of phage preparation $6 \mathrm{~h}$ prior to i.n. bacterial challenge did not provide complete protection but the ensuing disease process was much milder and complete clearance of the bacteria from infected lungs was observed by day $7(P>0.05)$. On the contrary, no decrease in bacterial counts was observed on administration of phage preparation $24 \mathrm{~h}$ prior to i.n. bacterial challenge $(P>0.05)$ (Fig. 5) and bacterial counts in the lungs were similar to the infected control group. It is

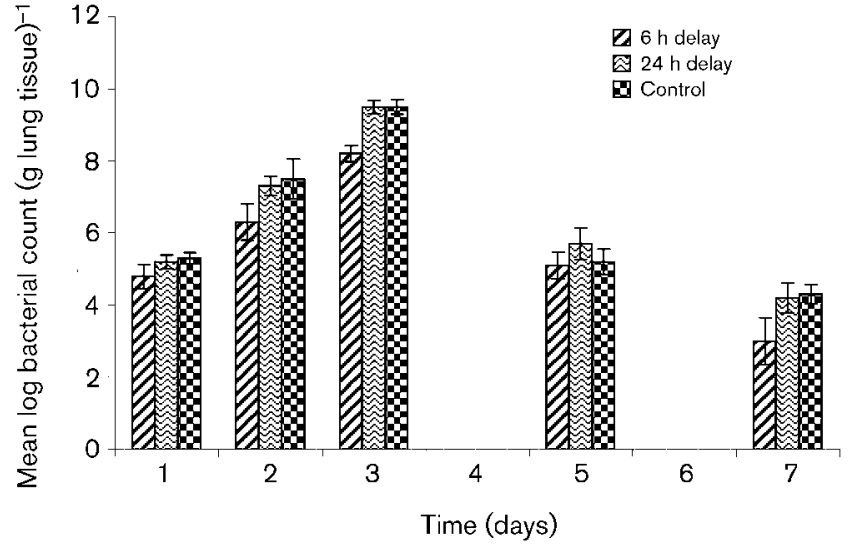

Fig. 4. Bacterial counts in lung tissue homogenate following infection with $K$. pneumoniae B5055 $\left(10^{8}\right.$ c.f.u. $\left.\mathrm{ml}^{-1}\right)$ in BALB/c mice (control) and delayed treatment with phage $\left(10^{10}\right.$ p.f.u. $\left.\mathrm{ml}^{-1}\right)$ ( $6 \mathrm{~h}$ delay and $24 \mathrm{~h}$ delay).

likely that the viable phage SS was encountered until $36 \mathrm{~h}$ post-injection in the lung tissue; however, after $12 \mathrm{~h}$ the phage concentration fell well below the optimum effective dose. Thus the low concentration of phage was unable to confer protection in mice following infection with $K$. pneumonia B5055.

In this study, the efficacy of a combined treatment of phage along with antibiotic was also evaluated in the acute infection model of lobar pneumonia. A single dose of amikacin alone, given once, was not found to be effective in this mouse model of experimental pneumonia and bacterial counts were similar to the untreated infected control animals (Fig. 6). The simultaneous administration of amikacin and phage preparation $\left(10^{10}\right.$ p.f.u. $\left.\mathrm{ml}^{-1}\right)$ along with bacterial challenge resulted in the maximum decrease in bacterial counts as compared to the animal groups in

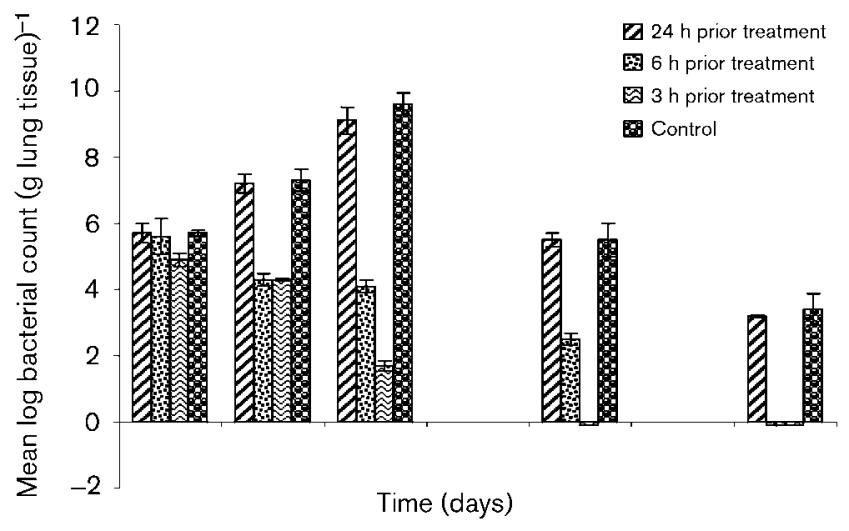

Fig. 5. Bacterial counts in lung tissue homogenate following phage administration at 3,6 and $24 \mathrm{~h}$ prior to bacterial challenge compared to an untreated control. 
which amikacin and phage were administrated alone. However, the difference in the log reduction of bacteria in the group of mice that were administered phage along with antibiotic was not statistically significant $(P>0.05)$ as compared to the animal group treated with phage only. On the basis of these results of combined treatment with the antibiotic amikacin and phage, no additional advantage as compared to the group treated with phage preparation alone was seen. However, the slight difference in the bacterial numbers could be attributed to different mechanisms of action of antibiotics and phages, which together were able to check the growth of viable bacteria more effectively in vivo. The combined treatment of phage and antibiotic, however, could prove more effective in vivo as this approach would provide limited opportunities for the emergence of resistance, which otherwise is likely to develop following monotherapy with either of the two agents.

The results of this study suggest that phage therapy has a potential to check the growth of K. pneumoniae B5055 in the respiratory tract if initiated at an appropriate time. However, there are still many technological challenges of phage therapy that need to be looked into before making general rules for phage products (Skurnik et al., 2007). Research on different aspects of phage therapy can help in the evolution of standardized phage banks having a comprehensive library of therapeutically approved phages. This will help in initiating phage therapy immediately after the identification of the pathogen.

Hence, further studies involving multiple phages (a cocktail) effective against multi-drug resistant wild-type Klebsiella isolates are warranted. Such an approach not only will be important from the point of view of controlling infections caused by multidrug-resistant $K$. pneumoniae strains but also will check the spread of infection within the hospital environment, especially in immunosuppressed patients, who are more prone to infection with K. pneumoniae during their stay in hospital.

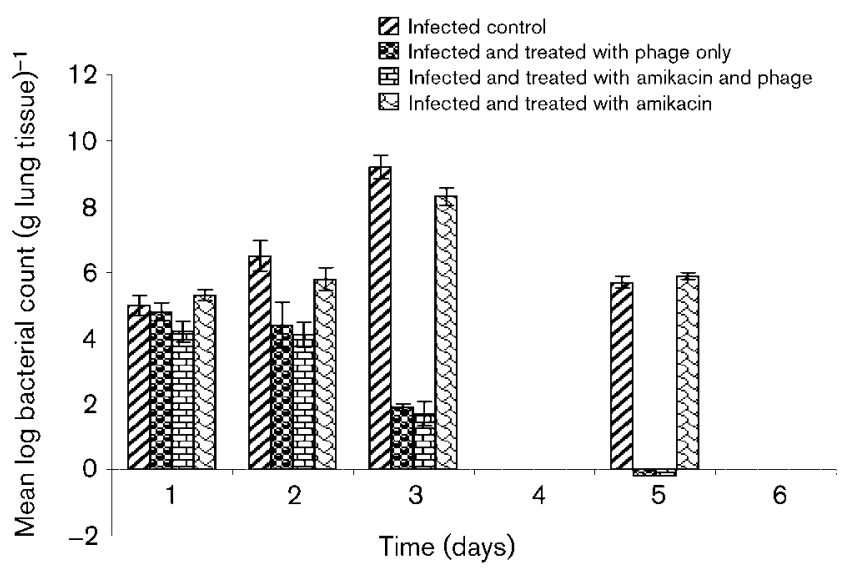

Fig. 6. Bacterial counts in lung tissue homogenate following combined therapy with phage and amikacin in BALB/c mice

\section{REFERENCES}

Ackermann, H. W. (2001). Frequency of morphological phage descriptions in the year. Arch Virol 146, 843-857.

Adams, M. (1959). Bacteriophages. New York: Intersciences.

Bogovazova, G. G., Voroshilova, N. N. \& Bondarenko, V. M. (1991). The efficacy of Klebsiella pneumoniae bacteriophage in the therapy of experimental Klebsiella infection. Zh Mikrobiol Epidemiol Immunobiol 4, 5-8 (in Russian).

Bogovazova, G. G., Voroshilova, N. N., Gorbatkova, G. A., Bondarenko, V. M., Kazakova, T. B., Mamleeva, A. G., Sirnov, V. D., Glukharev, I. A., Erastova, E. I. \& other authors (1992). Immunobiological properties and therapeutic effectiveness of preparations from Klebsiella bacteriophages. Zh Mikrobiol Epidemiol Immunobiol 3, 30-33 (in Russian).

Bradley, D. E. (1967). Ultrastructure of bacteriophages and bacteriocins. Bacteriol Rev 31, 230-314.

Carpenter, J. L. (1990). Klebsiella pulmonary infections: occurrence at one medical center and review. Rev Infect Dis 12, 672-682.

Cerveny, K. E., DePaola, A., Duckworth, D. H. \& Gulig, P. A. (2002). Phage therapy of local and systemic disease caused by Vibrio vulnificus in iron-dextran-treated mice. Infect Immun 70, 6251-6262.

Chhibber, S. \& Bajaj, J. (1995). Polysaccharide iron regulated cell surface protein conjugated vaccine: its role in protection against Klebsiella pneumoniae induced lobar pneumonia. Vaccine 13, 179-189.

Doern, G. V. (1995). Trends in antimicrobial susceptibility of bacterial pathogens of respiratory tract. Am J Med 99, 3S-7S.

Ellis, E. L. \& Delbruck, M. (1939). The growth of bacteriophage. J Gen Physiol 22, 365-384.

File, T. M. (2000). The epidemiology of respiratory tract infections. Semin Respir Infect 15, 184-194.

Goodridge, L., Gallacci, A. \& Griffiths, M. W. (2003). Morphological, host range and genetic characterization of two coliphages. Appl Environ Microbiol 69, 5364-5371.

Graybill, J. R., Marshall, L. W., Charache, P., Wallace, C. K. \& Melvin, V. B. (1973). Nosocomial pneumonia. A continuing major problem. Am Rev Respir Dis 108, 1130-1140.

Hanlon, G. W. (2007). Bacteriophages: an appraisal of their role in the treatment of bacterial infections. Int J Antimicrob Agents 30, $118-128$.

Hansen, D. S., Gottschau, A. \& Kolmos, H. J. (1977). Epidemiology of Klebsiella bacteraemia: a case control study using Escherichia coli bacteraemia as control. J Hosp Infect 38, 119-132.

Hervas, J. A., Alomar, A., Salva, F., Reina, J. \& Benedi, V. J. (1993). Neonatal sepsis and meningitis in Mallorca Spain, 1977-1991. Clin Infect Dis 16, 719-724.

Jay, S. J. (1983). Nosocomial pneumonia. Nosocomial Infect 74, 221-223. Leowski, J. (1986). Mortality from acute respiratory infections in children under 5 years of age. World Health Stat Q 39, 138-144.

Levin, B. R. \& Bull, J. J. (1996). Phage therapy revisited: the population biology of a bacterial infection and its treatment with bacteriophage and antibiotics. Am Nat 147, 881-898.

Maloney, S. A. \& Jarvis, W. R. (1995). Epidemic nosocomial pneumonia in the intensive care unit. Clin Chest Med 16, 209-223.

Mathur, M. D., Bidhani, S. \& Mehndiratta, P. L. (2003). Bacteriophage therapy: an alternative to conventional antibiotics. J Assoc Physicians India 51, 593-596.

Matsuzaki, S., Rashel, M., Uchiyma, J., Ujihara, T., Kuroda, M., Ikeuchi, M., Fujieda, M., Wakiguchi, J. \& Imai, S. (2005). 
Bacteriophage therapy: a revitalized therapy against bacterial infectious diseases. J Infect Chemother 11, 211-219.

McVay, C., Velasquez, S. M. \& Fralick, J. A. (2007). Phage therapy of Pseudomonas aeruginosa infection in a mouse burn wound model. Antimicrob Agents Chemother 51, 1934-1938.

Meyer, K. S., Urban, C., Eagan, J. A., Berger, B. J. \& Rahal, J. J. (1993). Nosocomial outbreak of Klebsiella infection resistant to late generation cephalosporins. Ann Intern Med 119, 353-358.

Nishi, T. \& Tsuchiya, K. (1980). Therapeutic effects of cefotiam and cefazolin on experimental pneumonia caused by Klebsiella pneumoniae DT-S in mice. Antimicrob Agents Chemother 18, 549-556.

Podschun, R. \& Ullmann, U. (1998). Klebsiella spp. as nosocomial pathogens: epidemiology, taxonomy, typing methods, and pathogenicity factors. Clin Microbiol Rev 11, 589-603.
Sambrook, J., Fritsch, E. F. \& Maniatis, T. (1989). Molecular Cloning: a Laboratory Manual, 2nd edn, 11 (2), 56-2.60. Cold Spring Harbor, NY: Cold Spring Harbor Laboratory.

Skurnik, M., Pajunen, M. \& Kiljunen, S. (2007). Biotechnological challenges of phage therapy. Biotechnol Lett 29, 995-1003.

Soothill, J. S. (1992). Treatment of experimental infections of mice with bacteriophages. J Med Microbiol 37, 258-261.

Sulakvelidze, A., Alavidze, Z. \& Morris, J. G. (2001). Bacteriophage therapy. Antimicrob Agents Chemother 45, 649-659.

Thiel, K. (2004). Old dogma, new tricks-21st century phage therapy. Nat Biotechnol 22, 31-36.

Yadav, V., Sharma, S., Harjai, K., Mohan, H. \& Chhibber, S. (2003). Induction \& resolution of lobar pneumonia following intranasal instillation with Klebsiella pneumoniae in mice. Indian J Med Res 118, 47-52. 